\title{
Designing blended engineering courses
}

\author{
E.A.M. van Puffelen
}

This is a "Post-Print" accepted manuscript, which has been published in the Proceedings of the 45th SEFI Annual Conference 2017

This version is distributed under the Creative Commons Attribution 3.0 Netherlands License, which permits unrestricted use, distribution, and reproduction in any medium, provided the original work is properly cited.

Please cite this publication as follows:

E. A. M. van Puffelen (2017). Designing blended engineering courses.

Proceedings of the 45th SEFI Annual Conference 2017, 1308 - 1312.

You can download the published version at:

https://www.4tu.nl/cee/en/publications/ 


\title{
Designing blended engineering courses
}

\author{
E.A.M. van Puffelen \\ Leader Centre for Engineering Education \\ Wageningen University \& Research \\ Wageningen, Netherlands \\ E-mail: emiel.vanpuffelen@wur.nl
}

\begin{abstract}
Universities have to deal with larger differences of engagement between students and more need for outcomes-based teaching and learning that allows for differences in learning styles. In addition for engineers, the rapidly changing world brings the need to engage students in diverse learning.

Wageningen University \& Research is experiencing these trends. It tackles them with outcomes-based teaching and engaging students within a rich setting of blended learning. The resulting education programmes are rated as the best in the national surveys of the last twelve years.

This paper describes how to design such blended learning courses based on literature. It also reflects the experience of Wageningen University \& Research with its successful approach.

The prerequisites for course design are a well-constructed curriculum and properly formulated Intended Learning Outcomes (ILOS). The core of course design consists of selecting and combining different types of online and on-campus Teaching and Learning Activity's (TLAs). Generally a smart design of a combination of (many) types of TLAs is needed to create top-quality blended engineering courses. Student motivation and higher level Intended Learning Outcomes for engineering require rich on-campus TLAs that cannot be completely offered online.
\end{abstract}

Conference Key Areas: Open and Online Engineering Education; Curriculum Development; Attractiveness of Engineering Education; Gender and Diversity

Keywords: Course Design, Online, Diversity 


\section{INTRODUCTION}

Biggs and Tang [1] have analysed changes in the nature of higher education and they see them causing more diversity among students. Consequences are that universities have to deal with larger differences of engagement between students and more need for outcomes-based teaching and learning that allows for differences in learning styles. In the last five years the increased use of blended and online education has caused new diversity and learning style issues. In addition for engineers, the rapidly changing world brings the need to engage students in diverse learning [2].

Wageningen University \& Research is experiencing all these trends. It tackles them with outcomes-based teaching and engaging students within a rich setting of blended learning. That approach is part of the University Teaching Qualification Programme for new lecturers and also a focus for education innovation projects. Examples of those projects are shown on the innovation map of the 4TU Centre for Engineering Education [3]. The resulting education programmes are rated as the best in the national surveys of the last twelve years [4].

This paper describes how to design such blended learning courses based on literature in combination with the experience of Wageningen University \& Research.

\section{THE DESIGN OF BLENDED COURSES: LITERATURE AND EXPERIENCE.}

The approach of Wageningen University \& Research with designing blended courses, matches the literature findings described below.

\section{Prerequisites}

Course design should be based on a well-constructed curriculum and properly formulated intended learning outcomes (ILOS). This is not easily attained. An option is to use the CDIO Approach [5], which should yield the four levels of ILOs shown in Figure 1.

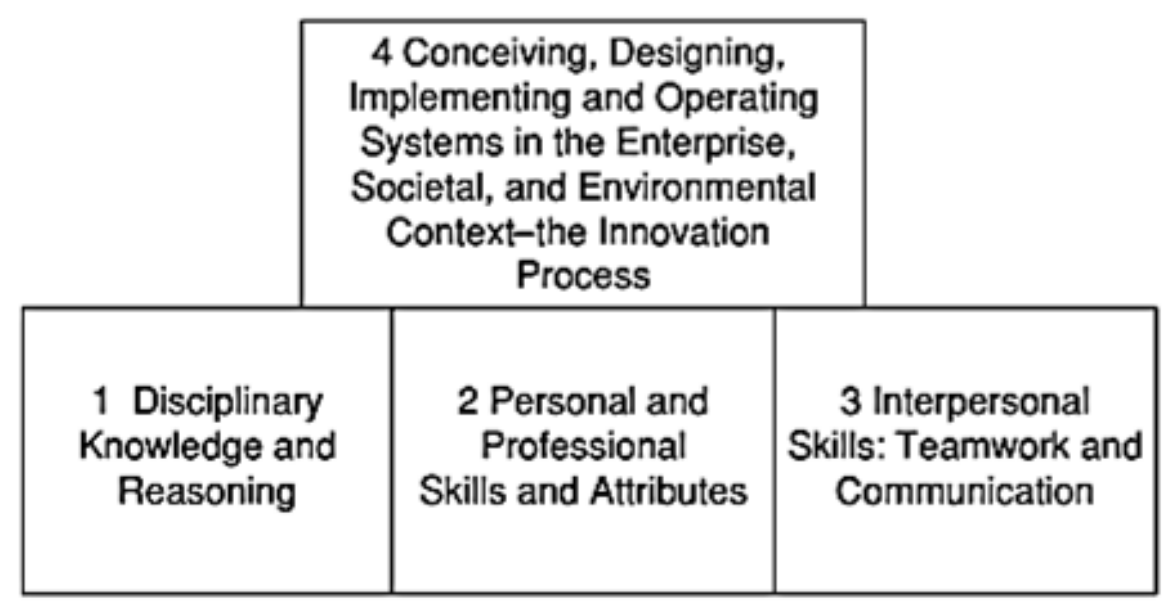

Fig. 1. Four levels of ILOs [5] 
There are many other approaches that usually yield ILOs on different levels, such as knowledge, skills and integration. The ILOs are the starting point in creating Teaching and Learning Activity's (TLAs) as well as Assessment. ILOs, TLAs and Assessment should be aligned [1], as shown in a clip [6] of Delft University of Technology.

\section{Selecting TLAs}

The core of course design is selecting TLAs. That requires an open mind on how students learn and considering the use of each available type of TLA. Laurillard [7, 8] synthesised a list of TLAs from theories of learning:

Acquisition: reading, watching, listening.

Inquiry: $\quad$ using resources to develop an evidence-based output.

Discussion: debating, questioning, answering, negotiating ideas.

Practice: $\quad$ acting, in the light of feedback, to achieve a goal or output.

Collaboration: working with others to achieve a joint output.

Production: making something for others to evaluate against agreed criteria.

All types of TLAs can be seen in traditional campus education and they can also be supported online. In both cases, the processes shown in Figure 2 are supported.

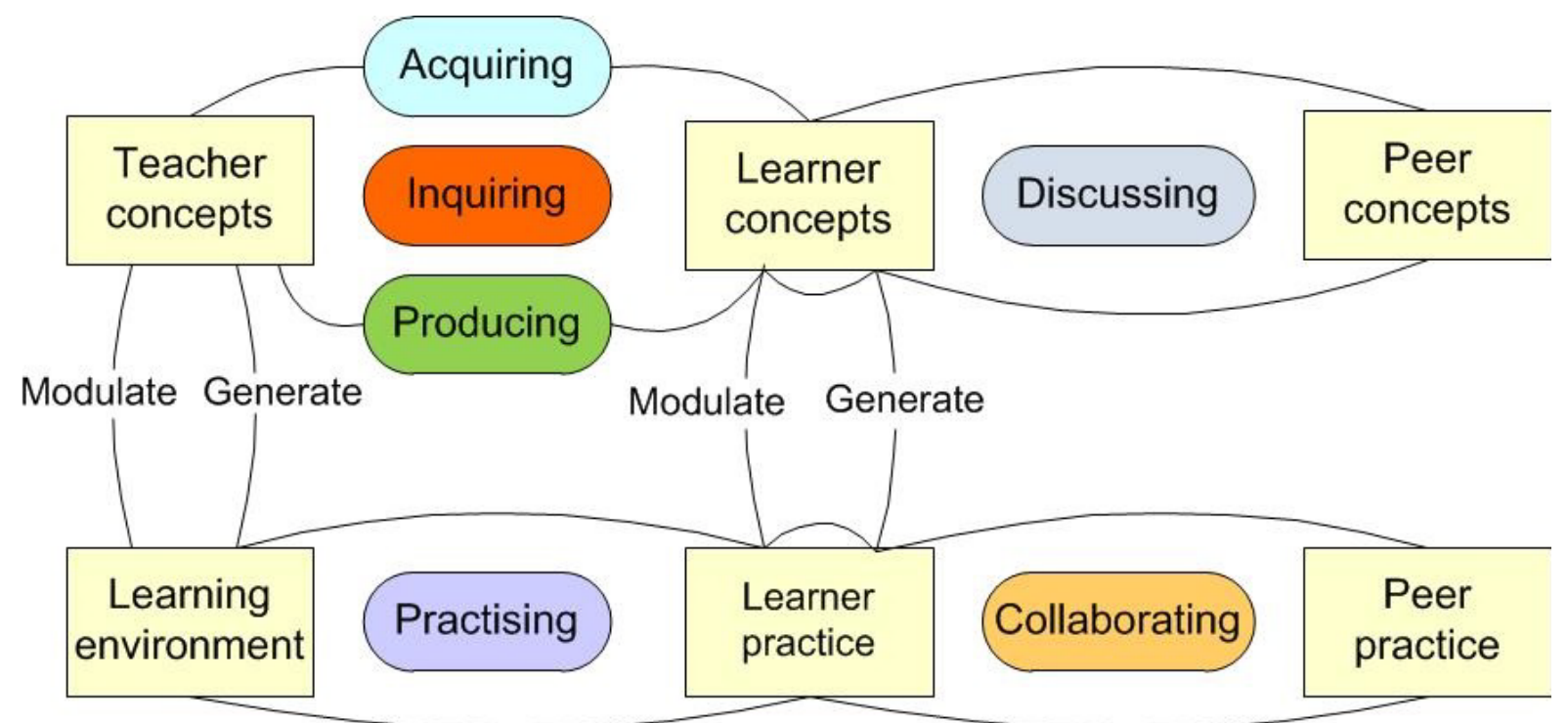

Fig. 2. TLAs and supported processes (based on Laurillard 7,8)

\section{Support of Learning Management Systems}

Most Learning Management Systems (LMS) were developed to support the TLAs shown on the left side of Figure 2 (acquiring, inquiring, producing and practising) and sometimes they extend to those on the right side of Figure 2 (discussing and collaborating) in newer versions. However, a separate, specialised LMS might still be required for the best options with the TLAs on the right side. 


\section{Combining TLAs}

Often, a large part of Figure 2 needs to be included in a course. One ILO might require different types of TLAs and the course set of ILOs might require more. In addition a workflow of TLAs (such as reading, developing evidence-based output, debating) might be needed to reach an ILO, especially for engineering. Differences in learning styles and learning theories also point in the direction of combining different TLAs. Last, but not least, combining TLAs is necessary to engage students and keep them surprised!

\section{Limits to the use of online TLAs}

Part of a smart design is the choice between on-campus and online versions of each TLA. Practical reasons (group size, available time, facilities, and curriculum standards) might dictate that choice. In general, the TLAs on the left side of the Figure 2 can be achieved with media resources (online, books etc.). Most universities have a long tradition in this and new developments, such as knowledge clips and Massive Open Online Courses (MOOCs), are creating more options.

In the last years Wageningen University \& Research has introduced a lot of knowledge clips and other online teaching methods. For instance the first half of the second year Food Technology use mainly knowledge clips instead of lectures, and most courses with practical's or tutorials have replaced parts of the activities with knowledge clips (clips on how to use equipment for example). The results show that students not always appreciate many knowledge clips, especially when the clips replace real classes and they feel a lack of teacher-student contact. In addition higher level engineering ILOs require on-campus collaboration work that cannot be completely offered online. Wageningen University \& Research has therefore started a project to evaluate the balance between online and on-campus TLAs.

\section{Combining evaluations of projects on innovative course design}

Wageningen University shares the information on new design of its courses, together with Delft University of Technology, Eindhoven University of Technology and the University of Twente using the online innovation map [3] of the 4TU. Centre for Engineering Education. For each project, information on approach, objective, strong points and recommendations is available. The combined evaluations of all projects constantly yields new lessons learned; like the ones described in this paper.

\section{CONCLUSIONS AND RECOMMENDATIONS}

The following conclusions and recommendations are based on this literature review and the experience of Wageningen University \& Research.

Course design should start with a well-constructed curriculum and properly formulated Intended Learning Outcomes (ILOs).

There are many types of Teaching and Learning Activity's (TLAs) and they can be grouped into TLAs involving acquisition, inquiry, discussion, practice, collaboration and production. 
A smart design of a combination of (many) types of TLAs is needed to create topquality university courses.

All types of TLAs can be seen in traditional campus education and they can also be supported online.

There are limits in replacing on-campus TLAs by online versions. It seems that students need a minimum amount of on-campus teacher-student contact and higher level engineering ILOs require rich on-campus collaboration work that cannot be completely offered online. Wageningen University \& Research has started a project to investigate this.

\section{REFERENCES}

[1] Biggs, J.B. and Tang, C., Teaching for Quality Learning at University. 4th Revised edition ed. 2011, Milton Keynes, United Kingdom: Open university press. 480.

[2] Kamp, A., Engineering Education in a Rapidly Changing World; Rethinking the Vision for Higher Engineering Education Second Revised Edition ed. 2016, Delft: Delft University of Technology, Faculty of Aerospace Engineering.

[3] 4TU.CEE. Innovation map 4TU Centre for Engineering Education. Cited 27 june 2017; Available from: https://www.4tu.nl/cee/en/research-innovation/.

[4] Looper, H.d., Belet, M. and Moor, A.d., Keuzegids Universiteiten (dutch; partial english translation: http://www.keuzegids.org/ol/gidsen/uni17/989 ). 2005-2017: Centrum Hoger Onderwijs Informatie.

[5] Crawley, E.F., Malmqvist, J., Östlund, S., Brodeur, D.R. and Edström, K., Rethinking Engineering Education; The CDIO Approach. 2 ed. 2014: Springer International Publishing. XVI, 311.

[6] Grob, M.A.G. and Kotkamp, E., Constructive Alignment, in TU Delft Beeldbank. 2014, Delft University of Technology. p. 0:05:44.

[7] Laurillard, D., Teaching as a Design Science: Building Pedagogical Patterns for Learning and Technology. 2012: Routledge Taylor \& Francis Group.

[8] Laurillard, D., Learning in the context of education; The conversational Framework, in Online Educa Berlin 2016. 2016: Berlin. 